\title{
Schooling Achievement among Rural Zimbabwean Children during a Period of Economic Turmoil
}

\author{
CATHERINE LAROCHELLE, JEFFREY ALWANG, AND NELSON TARUVINGA
}

\begin{abstract}
Zimbabwe suffered severe economic crisis in the decade before 2009, and anecdotal evidence indicates that public education suffered due to uncertainty about salary payments and inflation. As the country recovers, it is important to understand how this crisis affected schooling participation before and during the crisis. This study focuses on the relationship between schooling achievement, measured by enrollment and enrollment in the ageappropriate grade, and household economic conditions in rural Zimbabwe for 2001 and 2007. A wealth index is used to reflect household economic conditions. Results indicate that children in the bottom 20 percent of the economic status distribution were less likely than others to be enrolled or attend the age-appropriate grade in both periods, but the impact of the crisis on indicators of school attendance are surprisingly modest. Findings indicate that the economy may be poised to rebound as macro-economic conditions stabilize since schooling attainment did not slip substantially.
\end{abstract}

\section{Introduction}

Educational attainment is an important determinant of economic growth and poverty reduction. ${ }^{1}$ Despite well-documented economic and social benefits of education, schooling achievement remains low in many developing countries, and the poor continue to face important barriers to obtaining education. These obstacles can be exacerbated by negative economic shocks, particularly where capital markets are imperfect and the poor face borrowing constraints. Various factors influence school enrollment decisions, and poor children usually have lower enrollment rates than children from better-off families (Ersado 2005). Poor household heads frequently have low levels of schooling, and this, combined with limited financial resources, can contribute to intergenerational persistence of lagging school enrollment, low educational attainment, and poverty (Grimm 2011).

We thank the Central Statistical Office (now Zimbabwe National Statistics Agency, or ZIMSTAT) in Zimbabwe for providing the data and information on their use. This analysis was supported in part by a World Bank trust fund on poverty analysis. All views are those of the authors and do not reflect the views of ZIMSTAT, the World Bank, or its member countries. We alone are responsible for errors.

${ }^{1}$ See, e.g., Lucas (1988), Barro (1991), Mankiw et al. (1992), and Jacoby and Skoufias (1997).

Received September 1, 2014; revised April 3, 2015, and August 15, 2015; accepted September 1, 2015; electronically published March 28, 2016

Comparative Education Review, vol. 60, no. 2.

(c) 2016 by the Comparative and International Education Society. All rights reserved.

$0010-4086 / 2016 / 6002-0005 \$ 10.00$ 
A less-frequently explored consequence of poverty is the inability of poor children to remain in an age-appropriate grade, which may slow learning and have negative impacts on future earnings (Ferreira and Schady 2009). Demand for help at home for tasks such as farming, household chores, and care for younger siblings and the ill can prevent a child from attending school on a regular basis. Irregular attendance, in turn, can increase grade repetition. These factors can be exacerbated by economic shocks. Other factors linked to household economic status, such as nutrition and health affect the ability to remain in the age-appropriate grade. Malnutrition at young ages can result in poorer schooling outcomes and learning difficulties later in life. ${ }^{2}$ If poor children are more likely to delay school entry, repeat grades, and withdraw early from school, poverty may persist over time, especially when aggregate economic growth is not strong enough to reduce poverty in the short run. In such circumstances, special efforts may need to be taken to assist the poor in continuing their investments in education.

Attendance in school and enrollment in the age-appropriate grade may suffer following negative economic shocks, and the poor may suffer more. Theoretical models show ambiguous impacts of economic shocks on schooling, with the outcome depending on whether the (negative) income effect outweighs the (positive) price effect. ${ }^{3}$ In the presence of borrowing constraints and limited capital markets, shocks can theoretically have positive or negative effects on schooling. Empirical findings vary. Ferreira and Schady (2009) review this empirical evidence and find that in poorer developing countries in Africa and Asia, negative economic shocks are associated with lower school participation, while in developed countries schooling increases during periods of aggregate economic stress. Hyder et al. (2015) find that aggregate negative economic shocks in Malawi are negatively associated with participation in schooling and positively associated with the "grade attainment gap," a measure of age-grade mismatch.

Responses to economic shocks are of considerable importance for understanding the long-term consequences of acute economic and social crises afflicting Zimbabwe during 2000-2008. The Zimbabwe government had been running a fiscal deficit for the decade prior to 2000, but after the IMF stopped budgetary support in 1999 the situation spiraled out of control. In 2000 , the government embarked on a "fast track" land reform process associated with land invasions and the exodus of commercial farmers. The process damaged the commercial agriculture sector, reducing availability of (2010)

${ }^{2}$ See, e.g., Glewwe et al. (2001), Hoddinott and Kinsey (2001), Alderman et al. (2006), and Wisniewski

${ }^{3}$ The negative income effect comes from declines in incomes due to the negative shock; these declines make schooling less affordable to the household. The positive price effect results from a lower opportunity cost of attending school-fewer or less remunerative employment opportunities exist during an economic downturn. 
maize - the main staple - and exacerbating foreign exchange problems. By mid-2007, economic activity slowed dramatically and hyper inflationary forces began to erode the real economy. ${ }^{4}$ Asset poverty clearly worsened in rural Zimbabwe from 2001 to 2007 (Larochelle et al. 2014), but indicators of access to social services during the time did not indicate major problems.

Since its independence in 1980, the Zimbabwean government has placed a high priority on broadening access to primary and secondary schools and reducing gender imbalances. The objective of broad access was promoted through a number of policy initiatives; of recent note, the Basic Education Assistance Module (BEAM), introduced in 2001, was intended to promote participation and retention of students from vulnerable economic groups. Evidence on BEAM is mixed, but the program has not yet undergone a rigorous evaluation. In 2000, gross enrollment rates (GER) in primary school for Zimbabwe were 101 percent, compared to 82 percent for sub-Saharan Africa (World Bank 2014). The long-brewing economic crisis may have adversely affected long-standing investments, as by 2003 the GER had fallen moderately to 97 percent. The net enrollment rate (NER) in primary school also decreased by 4 percentage points, from 87 percent to 83 percent between 2001 and 2003 (World Bank 2014). While the measured 4 percentage point decline is relatively modest, anecdotal evidence shows that the decline continued as economic conditions worsened. ${ }^{5}$ It is important to understand how the crisis affected school participation and student progress. If it induced the poor to withdraw children from school, then prospects for broadbased growth during recovery may be compromised.

The Incomes, Consumption, and Expenditure Surveys (ICES) of 2001 and 2007, conducted by the Zimbabwe National Statistics Agency (ZIMSTAT), are used here to investigate the effect of household economic status on schooling decisions and educational attainment in rural areas. The paper investigates how household characteristics, such as education and employment conditions of the household head, presence of siblings of different ages, and degree of remoteness from schools affect educational outcomes. The data sets allow a detailed analysis of school enrollments and age-grade progression-the first such analysis for Zimbabwe using nationally representative data. The article contributes to the literature by employing a wealth index to reflect household economic status and systematically analyze the relationship between schooling and asset wealth in the rural Zimbabwe case. It investigates two measures of schooling participation-overall enrollment

\footnotetext{
${ }^{4}$ The official rate of inflation at the start of 2009 was 231 million percent, but private sector economists put the percentage as high as 65 followed by 107 zeros (Pilossof 2009).

${ }^{5}$ While the World Bank does not have data on GER and NER during 2004-11, the ICES data indicate that primary GER and NER were 93 percent and 73 percent, respectively, in 2007, an indication that schooling outcomes worsen during the economic crisis.
} 
in school and enrollment in the age-appropriate grade to reflect the static situation and progression over time.

Results show that household economic status is a strong predictor of school enrollment and being in the appropriate grade. Children in the bottom 20 percent of the economic status distribution are less likely than others to be enrolled in school or attend the age-appropriate grade. The effect of economic status on the probability of school participation is quantitatively similar between 2001 and 2007. However, in 2007 children from the wealthiest quintile are slightly less likely to attend the age-appropriate grade.

The article is structured as follows. The second section describes how household economic status was measured, and presents descriptive statistics on schooling achievement. A conceptual framework is introduced in the third section. The empirical specification of the main model is presented in the fourth section, and estimation results are shown in the fifth section. Concluding remarks are in the last section.

\section{Data and Methods}

The ICES is a nationally and provincially representative household survey used to compute national accounts, which has been enumerated at irregular intervals since the late 1980s. The survey contains information on sociodemographic characteristics, incomes, economic activities, and expenditures on more than 230 food and 330 non-food items. The fourth ICES, implemented from January through December 2001 and containing 12,192 rural and 6,490 urban households, is combined with the fifth, conducted from July 2007 through June 2008. The latter survey contains 11,221 rural and 2,973 urban households. The economic crisis during 2007-8 disrupted data collection and as a result, most of the observations in the fifth ICES were gathered in 2007.

While consumption expenditure is often used in the literature to reflect current household economic status in developing countries, the consumption expenditure data from the fifth ICES are not suitable for use due to the hyperinflation that characterized the period. With monthly inflation rates exceeding 1,000 percent by the end of 2007, the real value of consumption expenditures will depend on exactly when the product was purchased. To overcome the problem of hyperinflation, a wealth index is used to reflect household economic status for both surveys.

Wealth indexes and consumption expenditures can both be used as proxies for the unobserved concept of household long-term economic status. Neither measure is perfect; consumption expenditures are subject to short-term fluctuations while weights employed with a wealth index are vulnerable to criticism based on their perceived arbitrariness (Filmer and Pritchett 2001). The wealth index has the advantage of not requiring an adjustment for price 
differences over time and space. Recall biases are also less likely to be a problem as asset ownership can be easily measured (Moser and Felton 2007).

Studies have demonstrated the usefulness of a wealth index to examine determinants of education and health outcomes in the absence of consumption expenditure data. ${ }^{6}$ Use of a wealth index in this context has several advantages over consumption expenditures. First, the wealth index can capture dimensions relevant to educational outcomes ${ }^{7}$ other than wealth, such as access to electricity, clean drinking water, sanitation, and cooking fuel. By providing good quality lighting, electricity can reduce costs associated with studying; access to piped water reduces time needed to gather water, which should facilitate school attendance (Filmer and Pritchett 2001; Cockburn and Dostie 2007). Better sanitation reduces frequency of many illnesses and can promote more and regular school attendance. Fewer demands on time spent collecting firewood may also stimulate school attendance.

Second, the potential endogenous relationship between household economic status and children's school enrollment status is attenuated when the former is captured by a wealth index. Including consumption expenditures as an independent variable in a regression of the determinants of schooling attendance equation could result in violations of the statistical assumption of exogeneity. Because consumption expenditures might include schooling fees and other expenditures directly correlated with schooling attendance, such as uniform and transportation expenses, the estimated parameter reflecting the impact of expenditures on schooling will be biased. Short-term negative shocks to consumption expenditures caused by unobserved factors may also affect schooling outcomes while being much less likely to affect asset ownership (Jacoby and Skoufias 1997). Since the wealth index is a closer representation of the household's permanent income, unobserved factors affecting schooling are more unlikely to be correlated with asset ownership compared to consumption expenditures (Filmer and Pritchett 2001).

Wealth Index Estimation

Asset-based wealth indexes are formed by aggregating household assets into a single index. While disaggregated measures reflecting different dimensions of asset deprivation may be used, for example, Stoeffler et al. (2016), in the current case we are interested in the association between overall economic status and schooling. Thus we form an aggregate index. Several techniques have been used in the literature to estimate index weights. These include

\footnotetext{
${ }^{6}$ See, e.g., Filmer and Pritchett (1999, 2001), Bollen et al. (2002), Case et al. (2004), Rutstein and Johnson (2004), McKenzie (2005), and Gwatkin et al. (2007).

${ }^{7}$ Educational outcomes result from factors other than schooling. Parental time, peer effects, and environmental conditions, combined with schooling, contribute to learning. This article focuses on the schooling investments but recognizes that many of the factors considered have direct effects on school participation and indirect effects on schooling through their impacts on learning.
} 
factor analysis (FA), principal component analysis (PCA), multiple correspondence analysis (MCA), and polychoric PCA. ${ }^{8}$ Each method rests on different assumptions and some are more appropriate in certain contexts. However, with all the methods, weights are determined based on a statistical relationship between assets. All allow the wealth index to be represented as:

$$
W I_{i}=\sum_{j=1}^{n} w_{j} a_{i j} .
$$

$W I_{i}$ represents the wealth index score of household $i, a_{i j}$ is ownership of asset $j$, and $w_{j}$ 's are the weights which need to be estimated. The different approaches to construction of the wealth index employ different methods to estimate these weights.

Three broad categories of assets are included in the Zimbabwe wealth index: (i) durable goods, (ii) housing characteristics, and (iii) access to sanitation. Eight variables constitute the durable goods component: ownership of radio, television, refrigerator, bicycle, automobile, sewing machine, stove, and heater. Housing characteristics consist of dwelling type, main cooking fuel source, and access to electricity. Type of toilet facility and main source of drinking and cooking water comprise the sanitation component of the index. We use polychoric PCA to estimate the index because, since dwelling type, main cooking fuel, type of toilet facility, and main source of drinking water are all categorical variables, this technique is most appropriate.

\section{Descriptive Statistics}

The sample is composed of rural school-aged children-between 6 and 17-regardless of school attendance. ${ }^{9}$ To avoid potential problems with seasonal school attendance, ${ }^{10}$ the sample is restricted to observations collected during the same timeframe for both surveys. Eligible households were those interviewed between July 2001 and end-December 2001 for the fourth ICES and between July 2007 and end-December 2007 for the fifth. This leads to a final subsample of 5,109 (12,355) and 7,435 (17,302) rural households (school-aged individuals) in 2001 and 2007, respectively. In 2001, 79.6 percent of these children were enrolled in school compared to 80.6 percent in 2007 , a difference that is statistically significant at the 5 percent level. Among

\footnotetext{
${ }^{8}$ See, e.g., Sahn and Stifel (2000), Filmer and Pritchett (2001), Bollen et al. (2002), Moser and Felton (2007), Kolenikov and Angeles (2009), and Larochelle et al. (2014).

${ }^{9}$ The Zimbabwean school system has seven years of primary education (also referred to as "grade") followed by six years of secondary education ("form"). The lower age limits for primary and secondary school enrollment are 6 and 13 years. A student who has always been in school in the ageappropriate grade is expected to graduate at 19, but most students end formal schooling after 4 years of secondary education and taking the "O" level exams.

${ }^{10}$ School runs throughout the year in a three-term system, with two weeks of break between terms. However, school attendance may be seasonal and potential seasonality is restricted through use of a common time-frame.
} 
those attending school in 2001, 38.0 percent were enrolled in the correct school grade given their age. This proportion increased to 48.2 percent $(p-$ value $<.0001)$ in 2007 . Initial evidence thus shows that schooling participation increased between 2001 and 2007.

To gain insights relative to school achievement and household socioeconomic status and changes over time, schooling outcomes are tabulated with wealth index quintiles and children age for each survey year (tables 1 and 2). Wealth quintiles were based on pooled data from 2001 and 2007. The first quintile represents the poorest 20 percent, and the fifth quintile, the wealthiest 20 percent. ${ }^{11}$ School enrollment increased significantly between 2001 and 2007 for 6-7-year-old boys belonging to the first through fourth wealth quintiles and for girls of the same age for all wealth quintiles (table 1). This outcome could be an indication that school fees during the period did not keep pace with inflation, resulting in relatively lower costs of schooling in 2007. Younger children also have few options in the labor market, so changes in labor markets are likely to be unimportant for this group. Enrollment patterns are inconsistent for other age cohorts but generally show a decline in attendance in 2007. Growth in enrollment appears to be driven by large increases in enrollments among the youngest age group.

The synthetic cohort nature of the data can be exploited to compare enrollment rates for the 2001 age group with their corresponding age group in 2007. For example, 8-9-year-olds in 2001 correspond to 14-15-year-olds in 2007. In 2001, the enrollment rate was 5.4 and 2.9 percentage points higher for 8-9-year-old boys and girls, respectively, belonging to the wealthiest quintile compared to the poorest quintile. In 2007, the enrollment gap between 14-15-year-old boys and girls in the poorest and richest quintile grew to 19.5 and 21.4 percentage points, suggesting that wealth inequality problems prevailing in 2001 grew over time. In 2001, 14-15-year-old school enrollment rates were 17.4 and 20.8 percentage points higher for the boys and girls, respectively, in the wealthiest compared to the poorest quintile. While 14-15-year-olds from wealthier quintiles had lower rates of dropout in 2001, the gap grew by 2.1 and 0.6 percentage points by 2007. During the economic crisis, poorer children were more likely to drop out compared to wealthier ones.

Compared to 2001, in 2007, lower school attendance is more prevalent as age increases, and the attendance decline is more pronounced for boys than girls. Compared to 2001, the school enrollment rate in 2007 among boys between 10 and 11 years old is statistically lower for those belonging to the first, second, and third wealth quintiles while none of the differences are statistically significant for girls in the same age bracket. School enrollment

\footnotetext{
${ }^{11}$ Since quintiles are based on pooled wealth index and poverty is higher in 2007 , the first quintile includes more observations from the 2007 survey while the fifth quintile includes fewer.
} 
TABLE 1

School Enrollment Rates by Wealth Quintile, Age Group, Gender, and Survey Year, Rural Zimbabwe, 2001-7

\begin{tabular}{|c|c|c|c|c|c|c|c|}
\hline \multirow[b]{3}{*}{ Age } & \multirow[b]{3}{*}{ Quintile } & \multicolumn{6}{|c|}{ School Enrollment } \\
\hline & & \multicolumn{2}{|c|}{$2001(\%)$} & \multicolumn{2}{|c|}{$2007(\%)$} & \multicolumn{2}{|c|}{$\% \Delta(2001$ to 2007$)$} \\
\hline & & Male & Female & Male & Female & Male & Female \\
\hline \multirow[t]{5}{*}{$6-7$} & 1 & 55.2 & 65.9 & 71.8 & 78.6 & $16.7^{* * *}$ & $12.7^{* * *}$ \\
\hline & 2 & 61.9 & 64.9 & 79 & 81.7 & $17.1^{* * *}$ & $16.8^{* * *}$ \\
\hline & 3 & 66.8 & 70.2 & 81.9 & 83.2 & $15.1^{* * *}$ & $13.0^{* * *}$ \\
\hline & 4 & 73.4 & 77.8 & 86.7 & 87.5 & $13.2^{* * *}$ & $9.7^{* *}$ \\
\hline & 5 & 71.7 & 77.7 & 78.8 & 88.4 & 7.1 & $10.7^{* * *}$ \\
\hline \multirow[t]{5}{*}{$8-9$} & 1 & 91.8 & 94.1 & 90.3 & 92.9 & -1.5 & -1.2 \\
\hline & 2 & 93.8 & 96.3 & 92.7 & 94.5 & -1.1 & -1.8 \\
\hline & 3 & 94.5 & 98 & 92.3 & 96.1 & -2.1 & -1.9 \\
\hline & 4 & 95.9 & 93.8 & 93.9 & 95.4 & -2 & 1.6 \\
\hline & 5 & 97.2 & 97 & 96.5 & 96.4 & -.7 & -.6 \\
\hline \multirow[t]{5}{*}{ 10-11 } & 1 & 93.6 & 94.1 & 88.2 & 92.3 & $-5.4^{* *}$ & -1.8 \\
\hline & 2 & 95.9 & 96.8 & 92.4 & 95.8 & $-3.5^{*}$ & -1 \\
\hline & 3 & 98.3 & 94.8 & 95.5 & 94 & $-2.8^{* *}$ & -.8 \\
\hline & 4 & 97.7 & 97.8 & 95.1 & 96.8 & -2.5 & -1 \\
\hline & 5 & 98 & 98.6 & 96.8 & 97.3 & -1.2 & -1.3 \\
\hline \multirow[t]{5}{*}{$12-13$} & 1 & 88 & 87.6 & 81.3 & 86.1 & $-6.7^{* *}$ & -1.5 \\
\hline & 2 & 90.2 & 91.7 & 88.5 & 90.5 & -1.6 & -1.2 \\
\hline & 3 & 89.4 & 92.2 & 87.8 & 91.5 & -1.6 & -.8 \\
\hline & 4 & 93.5 & 94.4 & 91.7 & 95 & -1.8 & .6 \\
\hline & 5 & 91.9 & 90.7 & 93.1 & 97.8 & 1.2 & $7.1^{* * *}$ \\
\hline \multirow[t]{5}{*}{$14-15$} & 1 & 64.2 & 61.2 & 60.7 & 53.7 & -3.5 & $-7.5^{*}$ \\
\hline & 2 & 73.7 & 66.2 & 71.8 & 74.4 & -1.9 & $8.2^{* *}$ \\
\hline & 3 & 76.6 & 75.7 & 68.3 & 76 & $-8.3^{* *}$ & .3 \\
\hline & 4 & 80 & 74 & 72.9 & 83.6 & $-7.1^{*}$ & $9.7^{* *}$ \\
\hline & 5 & 81.6 & 82 & 80.2 & 75.1 & -1.4 & -6.9 \\
\hline \multirow[t]{5}{*}{$16-17$} & 1 & 40.9 & 35 & 36.2 & 32.9 & -4.6 & -2.1 \\
\hline & 2 & 50 & 43.3 & 41 & 39.6 & $-9.0^{*}$ & -3.7 \\
\hline & 3 & 58 & 54 & 52.4 & 53.3 & -5.6 & -.6 \\
\hline & 4 & 64.2 & 53.9 & 49.6 & 51.3 & $-14.6^{* * *}$ & -2.6 \\
\hline & 5 & 61.1 & 53.4 & 63 & 53.5 & 1.9 & .1 \\
\hline Total & & 79.7 & 79.6 & 79.3 & 81.7 & -.3 & $2.2^{* * *}$ \\
\hline
\end{tabular}

rates among 14-15-year-olds declined by about 8 percentage points for girls belonging to the poorest quintile and boys belonging to the third and fourth wealth quintiles. Enrollment among boys in the 16-17-year-old age group fell for all but those in the wealthiest quintile. These patterns from rural Zimbabwe differ from those reported in Thomas et al. (2004), who investigate schooling outcomes during the 1998 economic and financial crisis in Indonesia. They find evidence that in poor households schooling enrollment of young children decreased but the education of older children was protected.

The general trend in rural Zimbabwe is also toward increased enrollment in the age-appropriate grade in 2007 compared to 2001. The trend is strongest for older children and girls. Boys between 8 and 9, and 10 and 11 
SCHOOLING ACHIEVEMENT AMONG RURAL ZIMBABWEAN CHILDREN

TABLE 2

Enrollment in the Age-Appropriate Grade, Given School Participation, by Wealth Quintile, Age Group, Gender, and Survey Year, Rural Zimbabwe, 2001-7

\begin{tabular}{|c|c|c|c|c|c|c|c|}
\hline \multirow[b]{3}{*}{ Age } & \multirow[b]{3}{*}{ Quintile } & \multicolumn{6}{|c|}{ Age-Appropriate Grade } \\
\hline & & \multicolumn{2}{|c|}{$2001(\%)$} & \multicolumn{2}{|c|}{$2007(\%)$} & \multicolumn{2}{|c|}{$\% \Delta(2001$ to 2007$)$} \\
\hline & & Male & Female & Male & Female & Male & Female \\
\hline \multirow[t]{5}{*}{$6-7$} & 1 & 100.0 & 100.0 & 100.0 & 100.0 & .0 & .0 \\
\hline & 2 & 100.0 & 100.0 & 100.0 & 100.0 & .0 & .0 \\
\hline & 3 & 100.0 & 100.0 & 100.0 & 100.0 & .0 & .0 \\
\hline & 4 & 100.0 & 100.0 & 100.0 & 100.0 & .0 & .0 \\
\hline & 5 & 100.0 & 100.0 & 100.0 & 100.0 & .0 & .0 \\
\hline \multirow[t]{5}{*}{$8-9$} & 1 & 27.4 & 38.2 & 35.8 & 45.1 & $8.4^{* *}$ & $6.9^{*}$ \\
\hline & 2 & 34.8 & 40.8 & 41.9 & 47.1 & $7.1^{*}$ & 6.3 \\
\hline & 3 & 39.0 & 46.1 & 41.8 & 48.0 & 2.8 & 1.9 \\
\hline & 4 & 43.3 & 51.7 & 51.3 & 52.7 & 8.0 & 1.0 \\
\hline & 5 & 39.3 & 55.6 & 41.0 & 60.1 & 1.7 & 4.5 \\
\hline \multirow[t]{5}{*}{$10-11$} & 1 & 21.2 & 27.7 & 36.7 & 36.6 & $15.5^{* * *}$ & $8.9^{* *}$ \\
\hline & 2 & 30.7 & 29.6 & 31.6 & 38.4 & 1.0 & $8.8^{* *}$ \\
\hline & 3 & 30.7 & 35.8 & 38.4 & 41.9 & $7.7^{*}$ & 6.0 \\
\hline & 4 & 31.7 & 37.1 & 43.5 & 50.2 & $11.7^{* *}$ & $13.1^{* * *}$ \\
\hline & 5 & 41.6 & 44.4 & 36.9 & 51.4 & -4.7 & 7.0 \\
\hline \multirow[t]{5}{*}{$12-13$} & 1 & 17.9 & 21.1 & 26.0 & 27.9 & $8.1^{* *}$ & $6.9^{*}$ \\
\hline & 2 & 16.1 & 26.8 & 24.8 & 39.9 & $8.7^{* *}$ & $13.1^{* * *}$ \\
\hline & 3 & 27.4 & 31.2 & 28.8 & 45.3 & 1.4 & $14.2^{* * *}$ \\
\hline & 4 & 24.9 & 25.8 & 32.7 & 45.7 & $7.8^{*}$ & $19.9^{* * *}$ \\
\hline & 5 & 26.5 & 33.9 & 33.5 & 44.8 & 7.0 & $10.9^{* *}$ \\
\hline \multirow[t]{5}{*}{$14-15$} & 1 & 9.7 & 16.0 & 21.1 & 31.5 & $11.3^{* * *}$ & $15.5^{* * *}$ \\
\hline & 2 & 14.9 & 21.5 & 23.0 & 37.5 & $8.2^{* *}$ & $16.0^{* * *}$ \\
\hline & 3 & 14.7 & 28.4 & 33.3 & 35.5 & $18.6^{* * *}$ & 7.1 \\
\hline & 4 & 18.0 & 23.2 & 27.6 & 48.1 & $9.5^{* *}$ & $24.9^{* * *}$ \\
\hline & 5 & 24.7 & 25.2 & 18.8 & 43.4 & -5.8 & $18.2^{* * *}$ \\
\hline \multirow[t]{5}{*}{$16-17$} & 1 & 5.9 & 10.9 & 13.0 & 21.3 & $7.1^{*}$ & $10.4^{*}$ \\
\hline & 2 & 5.1 & 8.1 & 17.1 & 21.5 & $12.1^{* * *}$ & $13.4^{* *}$ \\
\hline & 3 & 14.2 & 11.8 & 18.9 & 29.8 & 4.7 & $18.0^{* * *}$ \\
\hline & 4 & 9.0 & 16.5 & 25.6 & 35.0 & $16.6^{* * *}$ & $18.5^{* * *}$ \\
\hline & 5 & 16.7 & 16.7 & 26.1 & 34.2 & $9.4^{*}$ & $17.5^{* * *}$ \\
\hline Total & & 34.6 & 41.6 & 43.9 & 52.6 & $9.3^{* * *}$ & $11.1^{* * *}$ \\
\hline
\end{tabular}

who belong to the lowest wealth quintile are 8.4 and 15.5 percentage points more likely to be enrolled in the age-appropriate grade in 2007 compared to 2001 (table 2). Girls between the ages of 12 and 17 are more likely to be attending the age-appropriate grade in 2007 than 2001, despite relatively stable school attendance. These differences are statistically significant for all groups, with the exception of 14-15-year-old girls from the third wealth quintile. Similar patterns are observed for boys. For example, 14-15-year-old boys belonging to the first, second, third, and fourth wealth quintiles are 11.3, 8.2, 18.6, and 9.5 percentage points more likely to attend the age-appropriate grade in 2007 compared to 2001. 
Being in an age-appropriate grade is the combination of two eventsage of entry into grade one and temporary movements in and out of school. While we cannot conclude with certainty, we speculate that the larger enrollment in the age-appropriate grade in 2007 is largely driven by greater proportion of children between 6 and 7 years of age being enrolled in school (table 1). The crisis has lowered the real cost of schooling due to school fees not keeping up with inflation, making delaying school entry due to financial constraints less of an issue. For older children, school enrollment slightly decreased over the period while attending the age-appropriate grade increased significantly. It is therefore possible to speculate that there are fewer movements in and out of school during the crisis compared to before. When out of school, children did not return. Improved progression through grades over time might also indicate that children in the same cohort who experienced difficulties progressing from grade to grade tended to respond by dropping out.

\section{Conceptual Framework}

Schooling decisions are assumed by economists to reflect long-term investments by the household in human capital. Individuals must consider time and money constraints when making this investment: enrollment of a child in school costs money and implies lost opportunities in terms of income and other benefits from forgone work. A child at school reduces time available for childcare for younger siblings and other household activities. Benefits to these long-term investments are felt upon completion of education and are reflected in higher earnings and greater well-being for educated children. In developing countries, social norms are strong and act as a binding contract across generations, where children take care of their parents in old age. Schooling costs are financed through saving, borrowing or by forgoing current consumption.

Conditions in labor and credit markets, household characteristics, such as wealth and demographics, and expectations about long-term returns to education all affect schooling decisions (Glewwe and Jacoby 2004). During an economic crisis, like the one experienced by Zimbabweans in the 2000s, where employment opportunities are limited, declines in wages lead to lower opportunity costs of schooling. Lower opportunity costs create a price (substitution) effect, which should translate into higher enrollment rates.

The substitution effect must be balanced against an income effect, associated with a reduction in financial resources caused by lower incomes. With a shortfall in income, investment in schooling becomes more costly to the household. Fewer financial resources might force households to allocate more time to earning activities, reducing children's time available for schooling. If credit is not readily available, schooling investments will depend on 
household financial resources ( Jacoby and Skoufias 1997). In rural Zimbabwe during the economic crisis, formal credit virtually disappeared and informal credit became exceedingly scarce. As a result, schooling investments had to be financed through forgoing current consumption, asset sales, and other savings.

Studies consistently show an important income effect-children of the poorest households are less likely to attend school (Jacoby 1994; Lincove 2009; Grimm 2011). In an economic crisis, income losses are likely to lower school attendance through this effect (Hyder et al. 2015). The net impact of the substitution and income effects depends on which effect dominates and is thus unknown (Thomas et al. 2004).

In rural Zimbabwe, school fees are zero, although many schools charge levies for building fees, and families must buy uniforms and books/supplies. During the economic crisis, few students were forced from school for nonpayment of levies so that the real cost of school to the households likely fell between 2001 and 2007 (Chakanyuka et al. 2009). However, the overall impact of household wealth on schooling is ambiguous. If possibilities to smooth consumption were more limited during the economic crisis (making educational investment more costly in terms of forgone consumption), wealth should have a greater influence on schooling decisions in 2007 compared to 2001.

Parental preferences toward schooling are linked to educational outcomes. While these preferences are not directly observable, they are related to observed household characteristics. Female and educated adult household members are more likely to have positive attitude toward schooling, which in turn can stimulate children's participation in school (Weir 2011). Household size and composition also play a role in schooling decisions by affecting children's shadow wages or the opportunity cost of time spent in school. For example, the presence of more young children or more old household members, all else held constant, should raise the demand for school-aged children (especially adolescents) in child or elder care. This increased demand will raise shadow wages and potentially lower school participation. This effect is likely to be more pronounced for girls than boys, as they are usually responsible for caring for younger siblings and the elderly.

As a summary of these conflicting effects, the following variables are expected to affect schooling decisions and outcomes. Household economic status is likely to be a key determinant, but the direction of the net income effect is a priori unknown because of the countervailing substitution and income effects. We expect the net effect to be different in 2007; the economic crisis is expected to weaken the substitution effect but, perhaps, increase the importance of wealth. Age and sex of the child will be included in the multivariate analysis, with ambiguous potential impacts about how the economic decline has affected the relationship between these variables and 
the schooling outcomes. Descriptive statistics indicate that older children are more likely to be enrolled in the age-appropriate grade in 2007 than in 2001 while overall schooling attendance is relatively stable. Girls more frequently take responsibility for caring for other household members, increasing their opportunity costs of schooling. The effect might have increased during the economic crisis if adult members have to work longer hours to compensate for lower income, or decreased if adult members work fewer hours. Wage employment opportunities are likely to be more limited for girls than boys, an effect that might be more pronounced during the crisis, lowering the opportunity cost of school attendance. Comparison of 2001 and 2007 data indicates that attendance in the age-appropriate grade has increased more for girls than boys, supporting the hypothesis of lower opportunity costs of schooling for girls in 2007.

Parental preferences for education of their children are reflected by a variable measuring education of the household head. The economic activity of the household head also reflects parental preferences. These variables also likely reflect investments in education such as home-learning and their impacts on school participation should be interpreted considering both the preference and indirect learning effects. Household composition, particularly the number of younger children, will affect decisions based on its effect on the opportunity cost of having children in school. This cost is expected to fall during the economic crisis. Variables measuring the distance to schools are also expected to affect the cost of education but might also capture effects of factors such as isolation and peer group effects, which have more indirect effects on school participation through learning.

\section{Empirical Model}

Schooling decisions are made based on expected net benefits of educational investments, which depend on factors discussed above. The expected net benefit associated with education of the $i^{\text {th }}$ child $\left(y_{i}^{*}\right)$ can be expressed as:

$$
y_{i}^{*}=x_{i}^{\prime} \beta+\varepsilon_{i},
$$

where $x_{i}$ is a set of exogenous variables affecting schooling decisions, and $\beta$ is a vector of parameters to be estimated. Equation (2) implicitly assumes that all relevant variables having a systematic effect on the expected net benefits are observed. Unobserved factors are assumed to be subsumed into $\varepsilon_{\mathrm{i}}$, a random error term. The expected benefits of education investments are not directly observed. Whether a child is enrolled in school and, conditional on school attendance, whether she is in the age-appropriate grade are observed. Age-appropriate enrollment is defined as being in at least the proper grade for age; that is, children who may have skipped a grade are considered to be 
in the age-appropriate grade. These observed outcomes can be expressed using binary variables. Enrollment in the age-appropriate grade can be represented by the dummy variable $y_{i}^{C}$ :

$y_{i}^{C}=1$ if the child is enrolled the age-appropriate grade,

$y_{i}^{C}=0$ if the child is NOT enrolled the age-appropriate grade.

Changes in constraint values, costs or returns to education may induce the child to enter and leave school. Enrollment in the age-appropriate grade is observed conditional on enrollment, which can be represented by the dummy variable $y_{i}^{S}$ :

$$
\begin{aligned}
& y_{i}^{S}=1 \text { if the child is enrolled in school, } \\
& y_{i}^{S}=0 \text { if the child is NOT enrolled in school. }
\end{aligned}
$$

Observed schooling outcomes can be estimated using a Heckman probit model (Van de Ven and Van Praag 1981) where the school attendance regression is referred to as the selection equation and enrollment in the ageappropriate grade is the outcome equation. Under this specification, the error terms implied by equations (3) and (4) follow a bivariate normal distribution (conditional mean equal to zero, and variance of 1 ), and the error terms between the selection and outcome equations are expected to have a nonzero correlation $(\rho \neq 0)$. Estimating the two equations separately would result in biased coefficients for the enrollment in age-appropriate grade equation if $\rho \neq 0$ (Van de Ven and Van Praag 1981).

Exogenous variables are (i) wealth (expressed in the form of index quintiles), (ii) child characteristics (age and gender), (iii) household head characteristics (age, sex, education, main economic activity), (iv) household composition (number of children below 6 years old, number of male and female of school-going age, and number of male and female adults), and (v) school accessibility (distance to primary and secondary school and distance to bus stop). Summary statistics for these variables are provided in tables 3 and 4 . Village-level fixed effects are included in the model and standard errors are clustered at the household-level. The fixed effect model mops up unobserved heterogeneity across villages, eliminating village-level omitted variable bias. Household-level clustering of the standard errors is appropriate since schooling decisions can be made for several children within a given household, and thus correlated.

In order for the Heckman probit model to be identified,,$^{12}$ the selection equation must contain at least one variable not included in the outcome

\footnotetext{
12 Technically, the nonlinear model can be identified through its functional form, but a plausible exclusion restriction will increase confidence in model identification.
} 
TABLE 3

Summary Statistics for Children of School Age, Rural Zimbabwe, 2001-7

\begin{tabular}{|c|c|c|c|c|}
\hline \multirow[b]{2}{*}{ Variables } & \multicolumn{2}{|c|}{2001} & \multicolumn{2}{|c|}{2007} \\
\hline & Mean & SD & Mean & $\mathrm{SD}$ \\
\hline Enrollment** & .800 & .400 & .810 & .400 \\
\hline Wealth index ${ }^{* * *}$ & -.120 & .980 & -.220 & .920 \\
\hline Quintile $1(\%)^{* *}$ & .217 & .412 & .229 & .420 \\
\hline Quintile $2(\%)^{* * *}$ & .180 & .385 & .202 & .402 \\
\hline Quintile $3(\%)^{* * *}$ & .217 & .412 & .239 & .427 \\
\hline Quintile $4(\%)^{* *}$ & .160 & .367 & .151 & .358 \\
\hline Quintile $5(\%)^{* * *}$ & .225 & .418 & .179 & .383 \\
\hline Child's gender $(1=$ male $)$ & .508 & .500 & .512 & .500 \\
\hline Child's age ${ }^{* *}$ & 11.409 & 3.391 & 11.320 & 3.395 \\
\hline $6-7^{*}$ & .166 & .372 & .174 & .379 \\
\hline $8-9$ & .171 & .377 & .173 & .378 \\
\hline $10-11$ & .171 & .376 & .172 & .377 \\
\hline $12-13$ & .171 & .377 & .177 & .382 \\
\hline $14-15^{* * *}$ & .171 & .377 & .157 & .363 \\
\hline $16-17$ & .149 & .356 & .147 & .354 \\
\hline HH head's gender $(1=$ male $)$ & .580 & .494 & .579 & .494 \\
\hline HH head's age ${ }^{* * *}$ & 48.120 & 14.440 & 49.330 & 15.690 \\
\hline \multicolumn{5}{|l|}{ HH head's education } \\
\hline No education $* * *$ & .190 & .400 & .170 & .370 \\
\hline Primary education ${ }^{* * *}$ & .620 & .490 & .530 & .500 \\
\hline Secondary education ${ }^{* * *}$ & .160 & .370 & .280 & .450 \\
\hline Post-secondary education ${ }^{* * *}$ & .030 & .160 & .020 & .130 \\
\hline \multicolumn{5}{|l|}{ HH head's main economic activity } \\
\hline Permanent paid employee ${ }^{* * *}$ & .130 & .336 & .057 & .231 \\
\hline Temporary employee* & .029 & .167 & .025 & .157 \\
\hline Communal/resettlement work $^{* * *}$ & .777 & .417 & .866 & .341 \\
\hline Own-account worker*** & .035 & .183 & .022 & .146 \\
\hline Other activities & .030 & .172 & .030 & .171 \\
\hline No. of female of school-going age $(6-19)^{* * *}$ & 1.700 & 1.270 & 1.610 & 1.190 \\
\hline No. of male of school-going age $(6-19)^{* * *}$ & 1.780 & 1.250 & 1.710 & 1.250 \\
\hline No. of female adults $(20+)^{* * *}$ & 1.280 & 680 & 1.320 & .700 \\
\hline No. of male adults $(20+)^{* * *}$ & .860 & .790 & .950 & .840 \\
\hline No. of young children $(0-5)^{* * *}$ & .970 & 1.010 & .890 & .940 \\
\hline Distance to primary school $(\mathrm{km})^{* * *}$ & 2.900 & 2.300 & 3.030 & 2.360 \\
\hline Distance to secondary school $(\mathrm{km})^{* * *}$ & 6.760 & 5.800 & 5.760 & 6.010 \\
\hline Distance to bus stop $(\mathrm{km})^{* * *}$ & 3.240 & 4.960 & 4.890 & 23.610 \\
\hline Number of observations & \multicolumn{2}{|c|}{12,355} & \multicolumn{2}{|c|}{17,302} \\
\hline
\end{tabular}

SOuRCE.-Authors' computations based on 2001 and 2007 ICES.

NoтE.-Tests are for significance of difference across years.

$* p<.1$.

** $p<.05$.

*** $p<.01$.

equation. This exclusion requirement is met by omitting the lowest child's age dummy variable, that is, 6 and 7 years old, in the equation on attending the age-appropriate grade. This variable affects whether a child attends school, but obviously cannot affect whether the child is in the age-appropriate grade.

\section{Results}

The model is estimated separately for 2001 and 2007 for rural Zimbabwe since a Wald test indicated that the estimated coefficients were dif- 
TABLE 4

Summary Statistics of Children Enrolled in School, Rural Zimbabwe, 2001-7

\begin{tabular}{|c|c|c|c|c|}
\hline \multirow[b]{2}{*}{ Variables } & \multicolumn{2}{|c|}{2001} & \multicolumn{2}{|c|}{2007} \\
\hline & Mean & SD & Mean & $\mathrm{SD}$ \\
\hline Age-appropriate grade, given school enrollment ${ }^{* * *}$ & .38 & .49 & .48 & .50 \\
\hline Wealth index ${ }^{* * *}$ & -.09 & 1.00 & -.18 & .94 \\
\hline Quintile 1 (\%) & .20 & .40 & .21 & .41 \\
\hline Quintile $2(\%)^{* * *}$ & .17 & .38 & .20 & .40 \\
\hline Quintile $3(\%)^{* * *}$ & .22 & .41 & .24 & .43 \\
\hline Quintile $4(\%)^{*}$ & .17 & .37 & .16 & .36 \\
\hline Quintile $5(\%)^{* * *}$ & .24 & .43 & .19 & .39 \\
\hline Child's gender $(1=$ male $)$ & .51 & .50 & .50 & .50 \\
\hline Child's age ${ }^{* * *}$ & 11.12 & 3.06 & 10.85 & 3.10 \\
\hline $6-7^{* * *}$ & .14 & .35 & .17 & .38 \\
\hline $8-9$ & .20 & .40 & .20 & .40 \\
\hline $10-11$ & .21 & .40 & .20 & .40 \\
\hline $12-13$ & .20 & .40 & .20 & .40 \\
\hline $14-15^{* * *}$ & .16 & .36 & .14 & .34 \\
\hline $16-17^{* *}$ & .10 & .29 & .09 & .28 \\
\hline HH head's gender $(1=$ male $)$ & .57 & .49 & .57 & .49 \\
\hline HH head's age a $^{* * *}$ & 48.06 & 14.21 & 49.03 & 15.49 \\
\hline \multicolumn{5}{|l|}{ HH head's education } \\
\hline No education ${ }^{* * *}$ & .17 & .38 & .15 & .35 \\
\hline Primary education ${ }^{* * *}$ & .63 & .48 & .53 & .50 \\
\hline Secondary education ${ }^{* * *}$ & .17 & .38 & .30 & .46 \\
\hline Post-secondary education ${ }^{* * *}$ & .03 & .16 & .02 & .14 \\
\hline \multicolumn{5}{|l|}{ HH head's main economic activity } \\
\hline Permanent paid employee ${ }^{* * *}$ & .13 & .33 & .06 & .23 \\
\hline Temporary employee & .02 & .15 & .02 & .15 \\
\hline Communal/resettlement work ${ }^{* * *}$ & .78 & .41 & .87 & .34 \\
\hline Own-account worker*** & .04 & .19 & .02 & .14 \\
\hline Other activities & .03 & .17 & .03 & .17 \\
\hline No. of female of school-going age $(6-19)^{* * *}$ & 1.71 & 1.27 & 1.60 & 1.18 \\
\hline No. of male of school-going age $(6-19)^{* * *}$ & 1.77 & 1.24 & 1.70 & 1.24 \\
\hline No. of female adults $(20+)^{* * *}$ & 1.28 & .68 & 1.32 & .70 \\
\hline No. of male adults $(20+)^{* * *}$ & .84 & .77 & .93 & .83 \\
\hline No. of young children $(0-5)^{* * *}$ & .96 & 1.00 & .88 & .93 \\
\hline Distance to primary school $(\mathrm{km})^{* * *}$ & 2.81 & 2.24 & 2.96 & 2.30 \\
\hline Distance to secondary school $(\mathrm{km})^{* * *}$ & 6.49 & 5.71 & 5.59 & 6.22 \\
\hline Distance to bus stop $(\mathrm{km})^{* * *}$ & 3.14 & 5.12 & 4.75 & 22.99 \\
\hline Number of observations & \multicolumn{2}{|c|}{9,835} & \multicolumn{2}{|c|}{13,933} \\
\hline
\end{tabular}

SOURCE.-Authors' computations based on 2001 and 2007 ICES.

NotE.-Tests are for significance of difference across years.

$* p<.1$.

** $p<.05$.

*** $p<.01$.

ferent. ${ }^{13}$ The marginal effects on the probability of being enrolled in school (first-stage selection equation) and the marginal effects on the probability of being in the age-appropriate grade (the second-stage outcome equation), conditioned on school participation are reported in table 5. At variable means, the estimated probability of attending school is 79.5 percent ( 80.6 percent) in 2001 (2007) and the probability of being in the correct grade, conditional

\footnotetext{
13 This finding of different coefficients is consistent with Ersado et al. (2003) who find that coefficients of determinants of consumption changed in Zimbabwe between 1990 and 1995.
} 


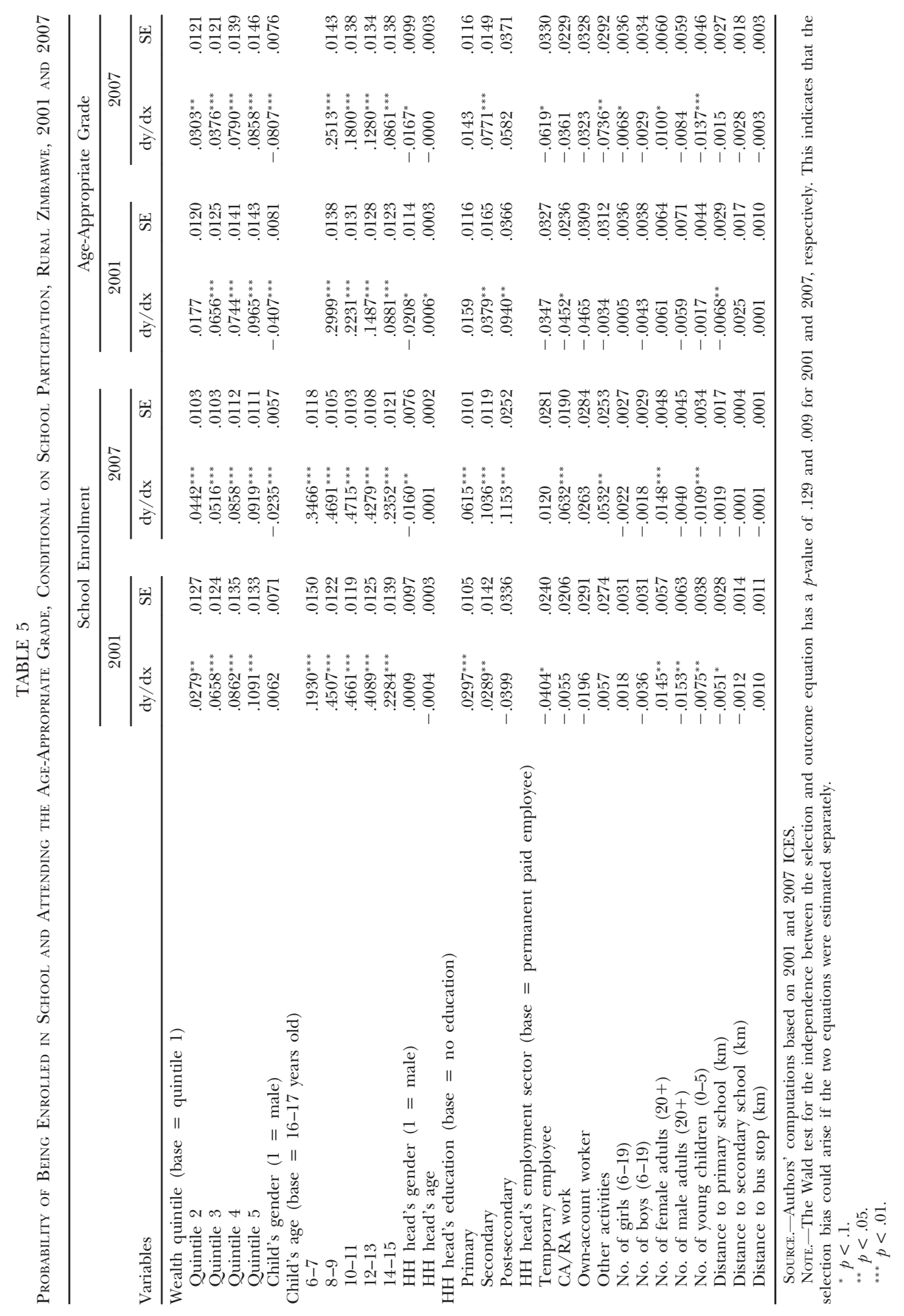


on school attendance is 37.8 percent (45.8 percent) for 2001 (2007). Overall, conditional on the covariates, school attendance has increased modestly while enrollment in the correct grade grew by 8 percentage points. Findings are consistent with the univariate analysis and indicate that child schooling outcomes are robust to the macroeconomic problems experienced in Zimbabwe during 2001-7.

\section{School Enrollment}

The probability of enrolling in school is higher for higher wealth index quintiles and the wealth enrollment effects are similar across years. All wealth index coefficients are significant below the one percent level in both survey years, showing that compared to the lowest quintile, school enrollment is higher for children in wealthier households. Wald tests subsequently determine whether school attendance varies significantly across wealth quintiles. For 2001, the probability of school enrollment is significantly greater for children belonging to the third wealth index quintile compared to those in the second, while children from the fourth quintile are more likely to be enrolled than those in the third. The enrollment probability is not statistically different between children in the fourth and fifth quintiles, suggesting that children from the top 40 percent of the wealth distribution have similar (relatively high) probabilities of being enrolled. In 2007, the probability of being enrolled in school is statistically different for children belonging to the fourth quintile compared to those in the third. The broad finding of a significant relationship between enrollment and household wealth is consistent with literature from a number of countries (Filmer and Pritchett 1999; Ersado 2005).

Wald tests are performed to test for the equality of the wealth quintile coefficients between 2001 and 2007 and determine whether the wealthparticipation relationship has changed. None of the wealth index quintile coefficients in the selection equation are significantly different across years when tested individually or jointly. ${ }^{14}$ Results support the notion that poor households face financial constraints to schooling, but the impact of financial constraints on school attendance is similar for 2001 and 2007.

The influence of other determinants of school participation changed between the surveys. In 2001, boys and girls had similar probabilities of being enrolled in school, while in 2007 girls are about 2.4 percentage points more likely to attend school (table 5). ${ }^{15}$ The age-enrollment profile also changed slightly. In comparison to the base age category-those between 16

\footnotetext{
${ }^{14}$ Wald tests for the equality of second, third, forth, and fifth index quintile coefficients between 2001 and 2007 have $p$-values of .26, .41, .85, and .38, respectively. The Wald test for the joint comparison of all index quintile coefficients has a $p$-value of .88 .

${ }^{15}$ The Wald test for the equality of the coefficients for child's sex has a $p$-value of .001 , indicating that the coefficient is statistically different between 2001 and 2007.
} 
and 17 years old - children aged between 10 and 11 are the most likely to be enrolled in school in both survey years. However, the probability of school attendance for this age group is statistically higher in $2007 .{ }^{16}$ In addition, as suggested by the descriptive statistics, the estimated coefficients indicate that 6 - and 7-year-old children are statistically more likely to be enrolled in school in 2007 than in 2001.

In 2007 , the probability of school participation is 1.6 percentage points lower for children living in male-headed households compared to those living in female-headed households, while this relationship was not significant in 2001 (table 5). This could be an indication that female household heads appreciate the role of children in providing old-age security and this appreciation grew during the period of economic uncertainty. This result is consistent with the expectation that an increase in future benefits from schooling will positively influence school enrollment. It is also consistent with Weir (2011) who finds that respondents with fewer opportunities to benefit from children's education are less likely to hold positive attitudes toward schooling.

The education of the household head has become a much stronger determinant of school enrollment in 2007. In 2001, children living in a household where the head completed primary or secondary school were about 3 percentage points more likely to attend school compared to children whose head had no formal education (table 5 ). This probability differential grew to 6.2 and 10.4 percentage points in 2007. The change is even of greater magnitude when the head completed post-secondary education; the probability of school participation was insignificant in 2001 compared to 11.5 percentage points higher in 2007 for children living in households whose head completed post-secondary education compared to those whose head had no formal education. This finding indicates a likelihood of growing inequalityover time, educational disparities and their economic consequences are likely to grow.

Attendance in school is also related to the sector of employment of the household head. The probability of school participation in 2001 for children in households headed by a temporary employee is 4.0 percentage points lower than for those whose head is a permanent paid employee. The difference is no longer statistically significant in 2007. Children of communal and resettlement workers are 6.3 percentage points more likely to attend school in 2007 compared to children whose head is a permanent employee.

In terms of household composition, findings are as expected and relatively consistent between survey years with one exception. The number of male adults in the household explains school enrollment in 2001 only. The

16 The Wald test for the equality of age coefficients for children 10 and 11 years old has a $p$-value of .03. 
results suggest that in 2001 the probability a child will be enrolled in school decreases by 1.5 percentage points with an additional male adult member. The number of female adults within a household is a significant and positive determinant of school participation in both 2001 and 2007. This is consistent with the view that greater household labor availability positively influences schooling participation. Dissimilarities between the effects of male and female adults on school attendance support the theory that preferences for schooling decisions is influenced by household composition. Females might value investment in schooling more than males do. The number of young siblings reduces the likelihood of being enrolled in school in both 2001 and 2007, reflecting the higher demand for child labor at home and higher opportunity cost of schooling.

In 2001, distance to the nearest primary school had a slight depressing effect on school enrollment, but no significant effects were found for the other distance variables. This finding is related to use of village fixed effects; a model without village fixed effects showed that longer distances to the nearest primary and secondary school had significant negative impacts on school enrollment in $2001(p=0)$. In 2007 , distance to primary school was significant and negative, while distance to secondary schools had a negative but insignificant impact on enrollment. This strong negative relationship between distance and school enrollment is not universally found in the literature. For example, Filmer and Pritchett (1999) find that school accessibility has a relatively small impact on school participation. Because our study focuses only on rural areas our results make intuitive sense. School accessibility clearly lowers the cost of education in rural areas, increasing school participation. The village fixed effects capture most of the unobservable components related to school quality and accessibility, leading to the insignificance of most distance variables.

Enrollment in the Age-Appropriate Grade

Household wealth is a significant determinant of being enrolled in the age-appropriate grade in both years. ${ }^{17}$ In 2001 , the probability of being in the age-appropriate grade, conditional on school participation, is 7-10 percentage points higher for children from the upper three wealth quintiles compared to those in the lower two quintiles. In 2007, the relationship between household wealth and age-appropriate enrollment was similar to that in 2001, but the magnitude of the wealth effect is slightly attenuated for the third and upper quintile. A Wald test indicates that the difference is only statistically significant for the third quintile. ${ }^{18}$ These results suggest that middle-class rural households faced more negative shocks or more difficulties coping with

\footnotetext{
${ }^{17}$ See the last four columns of table 5 .

${ }^{18}$ With a $p$-value of .05 .
} 
these shocks prior to 2007 compared to years prior to 2001, making children in this wealth bracket less likely to be enrolled in the age-appropriate grade in 2007. Also in 2007, the probability of being enrolled in the appropriate grade is three percentage points higher for children from the second wealth index quintile compared to those belonging to the poorest (in 2001, the difference was not statistically significant).

Attending the age-appropriate grade is more closely related to the notion of school achievement than school enrollment. Since being enrolled in an age-appropriate grade is correlated with prior negative schooling shocks, our results suggest that children from the poorest households have experienced more shocks, or are in households that are less able to manage the shocks, than children from less poor households are. In a longitudinal study on investments in schooling in rural Ethiopia, Mani et al. (2012) find that path dependence in schooling is stronger for children from high-income compared to low-income households. In poor households, children move in and out of school, while there are fewer enrollment fluctuations among children from better-off households. In poor households, negative household-level shocks affect enrollment while for children from wealthier households circumstances specific to the child are more likely to affect schooling participation (Mani et al. 2012).

Financial factors may force poor households to delay school entry or cause temporary withdrawal from school. In 2001 (2007) only 61 (75) percent of children between the age of six and seven years belonging to the poorest wealth quintile were enrolled in school compared to 75 (84) percent of those from the top quintile. However, by age 8-9 years, 93 (92) percent of the children in the poorest quintile are attending school compared to 97 (97) percent for the wealthiest. These results indicate that there is a demand for education among the poor, but financial constraints may constrain schooling investments.

Conditional on school enrollment, girls are significantly more likely to be enrolled in the age-appropriate grade than are boys. These findings follow those of many studies of schooling in less-developed countries (Grant and Behrman 2010; Mani et al. 2012). Grant and Behrman (2010) review studies from a number of countries and conclude that even in countries where boys had a traditional advantage over girls, girls have begun to surpass boys in terms of age-appropriate enrollment and grade since at least the early 1990s. They go on to examine cross-country information from 38 developing countries and show that while girls may be less likely to be enrolled, when enrolled they tend, in most regions, to progress through age-appropriate grades compared to boys. Mani et al. (2012), in a study from rural Ethiopia, find much stronger path dependence in schooling for girls than boys. Males are more likely to go in and out of school while girls usually stay in school or withdraw for reasons such as marriage. For rural Zimbabwe, we find that in 2001, the 
probability of being in the proper grade was 4.1 percentage points higher for girls than boys. In 2007, this differential increases to 8.1 percentage points, which may suggest that males are being withdrawn from school more often as a response to the economic crisis.

Older children are obviously ${ }^{19}$ less likely to be enrolled in the ageappropriate grade compared to younger ones, but the relationship is less pronounced in 2007. The lower real cost of attending school and the absence of opportunity outside of school in 2007 stimulate participation in school and thus the likelihood of being enrolled in the age-appropriate grade.

Living in a male-headed household is associated with a lower probability a child will be in the age-appropriate grade in both years. This indicates that in addition to being more concerned about schooling participation, females - when they are the sole decision maker in the household - are also more concerned about schooling achievement. This is consistent with our expectation that female-headed households might value more the role of children in providing old-age security, which requires both schooling enrollment and continued achievement. In 2001, the age of the household head was positively and significantly associated with enrollment in the proper grade, suggesting that older parents may have lower discount rates compared to young ones and will be more willing to postpone current for future consumption to maintain enrollment. The schooling attainment of the household head strongly influences the probability of being in the age-appropriate grade, but this effect was somewhat attenuated in 2007. Since there is a strong intergenerational persistence of educational achievement (as noted above), increasing the current educational level of all children could benefit the country's long-run human capital development.

As with school enrollment, the probability of attending the ageappropriate grade decreases with the number of young siblings. An additional child between 0 and 5 years old in a household decreases the probability of being in the age-appropriate grade by 1.4 percentage points in 2007 (the impact is not statistically significant in 2001). During economic crises, household financial resources are likely to be meager. If, as a result, adult members are forced to allocate more time to earning activities, the task of caring for young siblings will increase for children of school-going age.

Robustness Checks

In the annex, model robustness is examined using consumption expenditures from the 2001 survey. Results are consistent using both consumption expenditure and wealth index quintiles with the 2001 data. These results support the use of the wealth index as a measure of household well-being for both survey years. An additional robustness check examines the potential for

${ }^{19}$ Obvious because older children face more opportunities for disruption of their education. 
endogeneity of consumption expenditures, which might lead to bias in the estimated coefficients. The tests reject this form of bias (annex).

\section{Conclusion}

Schooling is an important determinant of a country's economic future, and during economic crises, schooling investments tend to suffer. In Zimbabwe, public support for primary and secondary education suffered in real terms during the economic hardship, but little evidence was available on the effects of the crisis on household decisions. Late enrollments and withdrawal of children from school are common means of coping with crises in many developing-country contexts and can lead to vicious cycles of ever-increasing impoverishment. In Zimbabwe, because the economic crisis was so deep, it is important to understand its impacts on household decisions about child schooling. This article examines factors affecting enrollment in school and enrollment in the age-appropriate grade during a period of extended economic crisis in Zimbabwe.

We find reason for optimism; parameters describing the relationship between schooling and concepts such as household economic status, individual and household characteristics, and other factors remained strikingly similar for both survey years. Schooling rates stayed the same for girls between 2001 and 2007 while declining slightly for boys. Both boys and girls are found to be more likely to be enrolled in the age-appropriate grade in 2007 compared to 2001. Observed changes in school attendance over the years are largely due to changes in underlying conditions and not to large differences in the "structure" of schooling decisions. This finding differs from evidence for responses to crises affecting other countries. For example, Thomas et al. (2004) find that in Indonesia, household spending on child education fell dramatically during the 1998 financial crisis and that the declines were steepest among the poor. ${ }^{20}$ In Zimbabwe, because much real expenditure on education is provided by the state, the costs to the household come in the form of opportunity costs. Opportunities in rural areas for child workers were limited during the crisis, so schooling enrollment has remained relatively high. However, to assess the full extent of the impacts of the crisis on education, it would be necessary to have data beyond 2007. Additional time might be needed to pick up on educational changes as enrollment tends to be a "sticky" phenomenon. For example, Hoddinott and Kinsey (2001) found that Zimbabwean children aged 12-24 months grew more slowly during time of drought, while Alderman et al. (2006) report that stunted preschoolers completed few schooling grades and started school later.

${ }^{20}$ Thomas et al. (2004) found that the spending declines were smaller in the rural sector. 
Household wealth is an important determinant of school enrollment and progression through grades in rural Zimbabwe. Children from the poorest wealth quintile are less likely than any other children to be enrolled or attend the age-appropriate grade. While Filmer and Pritchett (1999) identify separate patterns-in some regions the poor never enter school, while in others they enter but drop out - the rural poor in Zimbabwe suffer from both patterns. Like many other countries, special attention is needed to identify wealthrelated constraints to rural education. Contrary to expectations, there was no change in the relationship between wealth and school attendance between 2001 and 2007 and relatively small proportions of the decline in participation are due to deterioration in household wealth. Children from the wealthiest quintile were about 6 percentage points less likely to attend the age-appropriate grade in 2007 than in 2001, making poverty a less distinguishing determinant of schooling achievement in 2007.

In 2007, the educational achievement of the household head is a more important determinant of school enrollment than household economic status. This finding is consistent with evidence from other countries (Weir 2011). The intergenerational persistence of schooling achievement indicates that steps may be needed to promote continued enrollment of children from households headed by parents with limited education. Indicators of school participation are relatively good in Zimbabwe compared to many sub-Saharan African countries so that small steps to broaden participation might be fruitful.

Overall, the results suggest that the rural education system in Zimbabwe has weathered the storm of economic crisis. While the persistence of high enrollments is an important achievement, the article does not analyze the quality of schooling. This quality likely has suffered during the decline in economic conditions. Perceptions of the quality of teaching, however, enter into the enrollment decision, and evidence in this article at least hints that quality did not decline enough to discourage enrollments. During the worst period of hyperinflation, nominal salaries were devalued within hours of their receipt. and incentives to continue teaching were compromised. As conditions improve during the recovery, schooling status should also improve, and the evidence suggests that the crisis may not have lingering effects.

This study provides useful insights into policy debates in Zimbabwe. The BEAM program seems to have been fairly effective at protecting the most vulnerable households from the adverse effects of the economic crisis. Girls have not been disadvantaged relative to boys, but boys have fallen behind relative to girls. Under such circumstances, gender targets may be revised to consider how boys suffer during periods of economic hardship. Efforts to improve enrollment are important, and programs to reduce dropouts should be evaluated. The article did not conduct a benefit-cost analysis of the BEAM program, but it at least appears to be having a positive impact on enrollments. 


\section{Appendix}

\section{Robustness Checks}

Using the 2001 survey ${ }^{21}$ we reestimate the model using per capita consumption expenditures as the indicator of household long-term economic status. Results are consistent using both consumption expenditures and wealth index quintiles with the 2001 data (tables 5, A1). All consumption expenditures quintile coefficients are statistically significant ( $p$-value of 0 ) and similar to those of the wealth index but of smaller magnitude for higher wealth quintiles. Filmer and Pritchett (2001) also find that the measured gap between rich and poor is generally greater when using a wealth index. They interpret these disparities "as attenuation bias due to greater measurement error in consumption expenditures than in the wealth index. Error here is defined in relation to its use as a proxy for the relevant indicator of economic status in the analysis of education outcomes" (Filmer and Pritchett 2001, 122).

\section{Controlling for Endogeneity}

Consumption expenditures may be endogenous to short-term schooling decisions, and to examine potential bias associated with this endogeneity, we reestimate the 2001 model using the wealth index as an instrument for per capita consumption. Since the model considered is nonlinear, potential endogeneity is controlled for using a two-step estimation approach as proposed in Cameron and Trivedi (2009). The first step consists of performing a linear regression of per capita consumption expenditures on the set of regressors and the instrument (i.e., the wealth index) and then generating residuals from this regression. ${ }^{22}$ In the second step, the Heckman Probit is estimated including as an additional regressor the first-step residuals. The residual coefficient provides an opportunity to test the null hypothesis of exogeneity of per capita consumption in the schooling outcome equations using a robust Wald test.

The coefficient for the first-step residuals has a $p$-value greater than .1 in both the selection and outcome equations, leading to failure to reject the null. According to this measure, consumption expenditures are not endogenous to schooling decisions. In addition, the marginal effects on the probability of being enrolled in school and attending the age-appropriate under the assumption of endogeneity are nearly identical to those obtained without controlling for this potential endogeneity (table A1). Though, worth noting is that in the school participation equation the coefficient of the fifth quintile increases from 7.2 to 8.3 percentage points when per capita consumption expenditure is considered an endogenous regressor.

${ }^{21}$ As noted, using per capita consumption expenditures was not possible in 2007 due to the hyperinflation.

${ }^{22}$ The instrument, i.e. the wealth index. is highlv significant $(t$-value $=7.78)$ with expected sign. 


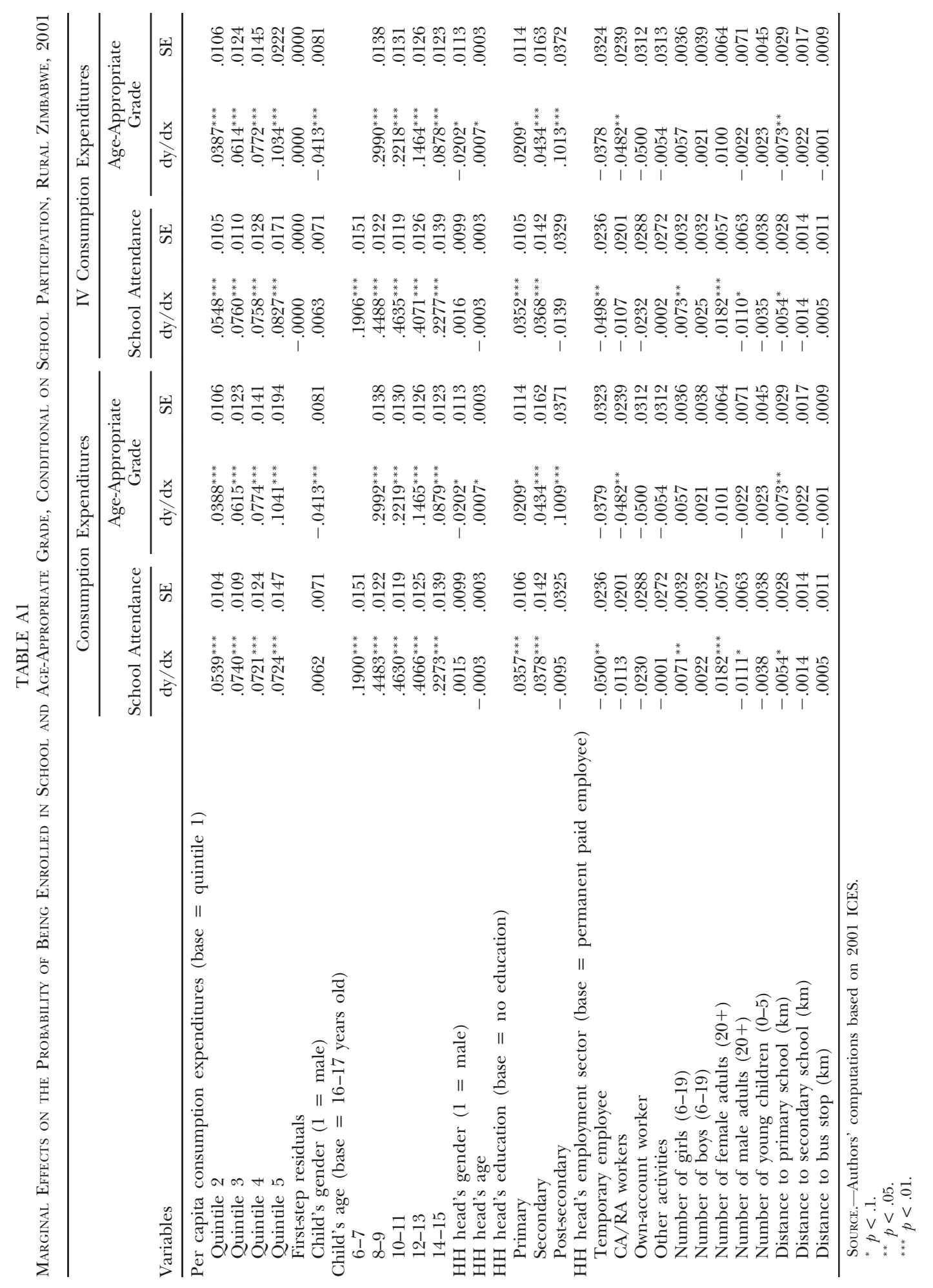




\section{References}

Alderman, Harold, John Hoddinott, and Bill Kinsey. 2006. "Long Term Consequences of Early Childhood Malnutrition." Oxford Economic Papers 58 (3): 450-74.

Barro, Robert J. 1991. "Economic Growth in a Cross Section of Countries." Quarterly Iournal of Economics 106 (2): 407-43.

Bollen, Kenneth A., Jennifer L. Glanville, and Guy Stecklov. 2002. "Economic Status Proxies in Studies of Fertility in Developing Countries: Does the Measure Matter?" Population Studies 56 (1): 81-96.

Cameron, A. Colin, and Pravin K. Trivedi. 2009. Microeconomics Using Stata. Lakeway Drive, TX: Stata.

Case, Anne, Christina Paxson, and Joseph Ableidinger. 2004. "Orphans in Africa: Parental Death, Poverty, and School Enrollment." Demography 41 (3): 483-508.

Chakanyuka, S., F. K. Chung, and T. Stevenson. 2009. The Rapid Assessments of Primary and Secondary Schools. Harare: National Education Advisory Board.

Cockburn, John, and Benoit Dostie. 2007. "Child Work and Schooling: The Role of Household Asset Profiles and Poverty in Rural Ethiopia." Lournal of African Economies 16 (4): 519-63.

Ersado, Lire. 2005. "Child Labor and Schooling Decisions in Urban and Rural Areas: Comparative Evidence from Nepal, Peru, and Zimbabwe." World Development 33 (3): 455-80.

Ersado, Lire, Harold Alderman, and Jeffrey Alwang. 2003. "Changes in Consumption and Saving Behavior before and after Economic Shocks: Evidence from Zimbabwe." Economic Development and Cultural Change 52 (1): 187-215.

Ferreira, Francisco H. G., and Norbert Schady. 2009. "Aggregate Economic Shocks, Child Schooling, and Child Health.” World Bank Research Observer 24 (2): 147-81.

Filmer, Deon, and Lant Pritchett. 1999. "The Effect of Household Wealth on Educational Attainment: Evidence from 35 Countries." Population and Development Review 25 (1): 85-120.

Filmer, Deon, and Lant Pritchett. 2001. "Estimating Wealth Effects without Expenditure Data-Or Tears: An Application to Educational Enrollments in States of India." Demography 38 (1): 115-32.

Glewwe, Paul, and Hanan G. Jacoby. 2004. "Economic Growth and the Demand for Education: Is There a Wealth Effect?" Lournal of Develobment Economics 74 (1): 33-51.

Glewwe, Paul, Hanan G. Jacoby, and Elizabeth M. King. 2001. "Early Childhood Nutrition and Academic Achievement: A Longitudinal Analysis." Lournal of Public Economics 81 (3): 345-68.

Grant, Monica J., and Jere R. Behrman. 2010. "Gender Gaps in Educational Attainment in Less Developed Countries." Population and Development Review 36 (1): $71-89$.

Grimm, Michael. 2011. "Does Household Income Matter for Children's Schooling? Evidence for Rural Sub-Saharan Africa." Economics of Education Review 30 (4): $740-54$.

Gwatkin, Davidson R., Shea Rutstein, Kiersten Johnson, Eldaw Suliman, Adam Wagstaff, and Agbessi Amouzou. 2007. Socio-Economic Differences in Health, Nutrition, and Population within Developing Countries. Washington, DC: World Bank. 
Hoddinott, John, and Bill Kinsey. 2001. "Child Growth in the Time of Drought." Oxford Bulletin of Economics and Statistics 63 (4): 409-36.

Hyder, Asma, Jere R. Behrman, and Hans-Peter Kohler. 2015. "Negative Economic Shocks and Child Schooling: Evidence from Rural Malawi." Development Southern Africa 32 (4): 458-76.

Jacoby, Hanan G. 1994. "Borrowing Constraints and Progress through School: Evidence from Peru." Review of Economics and Statistics 76 (1): 151-60.

Jacoby, Hanan G., and Emmanuel Skoufias. 1997. "Risk, Financial Markets, and Human Capital in a Developing Country." Review of Economic Studies 64 (3): 311-35.

Kolenikov, Stanislav, and Gustavo Angeles. 2009. "Socioeconomic Status Measurement with Discrete Proxy Variables: Is Principal Component Analysis a Reliable Answer?" Review of Income and Wealth 55 (1): 128-65.

Larochelle, Catherine, Jeffrey Alwang, and Nelson Taruvinga. 2014. "Inter-Temporal Changes in Well-Being during Conditions of Hyperinflation: Evidence from Zimbabwe." Lournal of African Economies 23 (2): 225-56.

Lincove, Jane Arnold. 2009. "Determinants of Schooling for Boys and Girls in Nigeria under a Policy of Free Primary Education." Economics of Education Review 28 (4): 474-84.

Lucas, Robert E., Jr. 1988. "On the Mechanics of Economic Development.” Lournal of Monetary Economics 22 (1): 3-42.

Mani, Subha, John Hoddinott, and John Strauss. 2012. "Long-Term Impact of Investments in Early Schooling-Empirical Evidence from Rural Ethiopia.” Iournal of Development Economics 99 (2): 292-99.

Mankiw, N. Gregory, David Romer, and David N. Weil. 1992. "A Contribution to the Empirics of Economic Growth.” Ouarterly Journal of Economics 107 (2): 40737.

McKenzie, David. 2005. "Measuring Inequality with Asset Indicators." Lournal of Population Economics 18 (2): 229-60.

Moser, Caroline, and Andrew Felton. 2007. "The Construction of an Asset Index Measuring Asset Accumulation in Ecuador.” CPRC Working Paper no. 87, Chronic Poverty Research Centre, http://r4d.dfid.gov.uk/PDF/Outputs/Chronic Poverty_RC/87Moser_Felton.pdf.

Pilossof, Rory. 2009. "Dollarisation in Zimbabwe and the Death of an Industry." Review of African Political Economy 36 (120): 294-99.

Rutstein, Shea Oscar, and Kiersten Johnson. 2004. "The DHS Wealth Index." In DHS Comparative Reports, No. 6, 1-71. Calverton, MD: ORC Macro.

Sahn, David E., and David C. Stifel. 2000. "Poverty Comparisons over Time and across Countries in Africa." World Development 28 (12): 2123-55.

Stoeffler, Quentin, Jeffrey Alwang, Bradford Mills, and Nelson Taruvinga. 2016. "Multidimensional Poverty in Crisis: Lessons from Zimbabwe." Lournal of Development Studies 52 (3): 428-46.

Thomas, Duncan, Kathleen Beegle, Elizabeth Frankenberg, Bondan Sikoki, John Strauss, and Graciela Teruel. 2004. "Education in a Crisis." Iournal of Develobment Economics 74 (1): 53-85. 
Van de Ven, Wynand PMM, and Bernard Van Praag. 1981. "The Demand for Deductibles in Private Health Insurance: A Probit Model with Sample Selection." Lournal of Econometrics 17 (2): 229-52.

Weir, Sharada. 2011. "Parental Attitudes and Demand for Schooling in Ethiopia." Lournal of African Economies 20 (1): 90-110.

Wisniewski, Suzanne L. W. 2010. "Child Nutrition, Health Problems, and School Achievement in Sri Lanka." World Development 38 (3): 315-32.

World Bank. 2014. World Development Indicators 2014. Washington, DC: World Bank. 